\title{
Study on Metering Scheme of Seismic Experiment for Shear Wall Built with Precast Hollow Slab
}

\author{
Zhijuan Sun ${ }^{1}$, Jiliang $\mathrm{Liu}^{2}$, Qinyan Zhao ${ }^{2 *}$ and Mingjin $\mathrm{Chu}^{2 \mathrm{w}}$ \\ ${ }^{1}$ School of Architecture, Yantai University, Yantai, 264005, China \\ ${ }^{2}$ School of Civil Engineering, Yantai University, Yantai, 264005, China
}

\begin{abstract}
Shear deformation is the most principal deformation in the lateral deformation of shear wall built with precast hollow slab which is designed to be strong shearing and weak bending. The special mechanical characteristic of the shear wall is the relative deformation of the concrete on both sides of vertical and inner joint respectively. The study introduces the measuring scheme of shear wall deformation and steel strain. The measuring method of shear deformation is designed and the device is used to measure horizontal and vertical relative deformation of the concrete near joints. It has been proved that the experimental measuring scheme can monitor the shear wall deformation and the steel strain successfully. The measuring methods of shear wall deformation and relative deformation are reasonable and feasible.
\end{abstract}

Keywords: Horizontal relative deformation, measuring scheme, shear wall built with precast hollow slab, shear wall deformation, vertical joint, vertical relative deformation.

\section{INTRODUCTION}

The precast concrete shear wall built with precast two-way hollow slabs is an innovated industrialization shear wall. It is made by pouring concrete into vertical and horizontal holes of the precast two-way hollow slabs that forms a whole structure element. To study the mechanical behaviors of the precast concrete shear wall with inner joint and vertical joint, a precast concrete shear wall, designed by the principle of strong shearing and weak bending, is quasi-statically tested under low cyclic lateral loads [1]. The deformation characteristics of the precast concrete shear wall are that the shear deformation accounts for a large proportion in the total deformation. The vertical and horizontal relative deformation occurring on the concrete of both sides of vertical joint and inner joints is a new special deformation characteristic. In this study, a measure scheme of the shear wall deformation and reinforcement strain is introduced, a method measuring shear deformation is designed, and a kind of measuring equipment to meter vertical and horizontal relative deformation is invented. It will provide some reference for the metering scheme of such structures.

\section{GENERAL SITUATION OF THE TEST}

A quasi-static test under a constant axial force is accomplished to study the mechanical behaviors of the precast concrete shear wall. The specimen is composed of an assembled monolithic concrete shear wall and cast-in-place edge members, the assembled monolithic concrete shear wall

*Address correspondence to this author at the School of Civil Engineering, Yantai University, Yantai, 264005, China; Tel: +86 535 6902606;

Fax: +86 535 6902606; E-mail: ZQY3242@126.com includes two precast two-way hollow slabs and cast-in-place concrete of the holes, and there is a vertical joint between the two precast two-way hollow slabs. The precast two-way hollow slab which has cross holes composing of vertical and horizontal holes is produced in the prefabricated-component factory. The design principle of the specimen is strong shearing and weak bending. Dimensions and assembly drawing of the specimen is shown in Fig. (1). The lateral load is hybrid controlled by load and displacement, and the test setup is shown in Fig. (2).

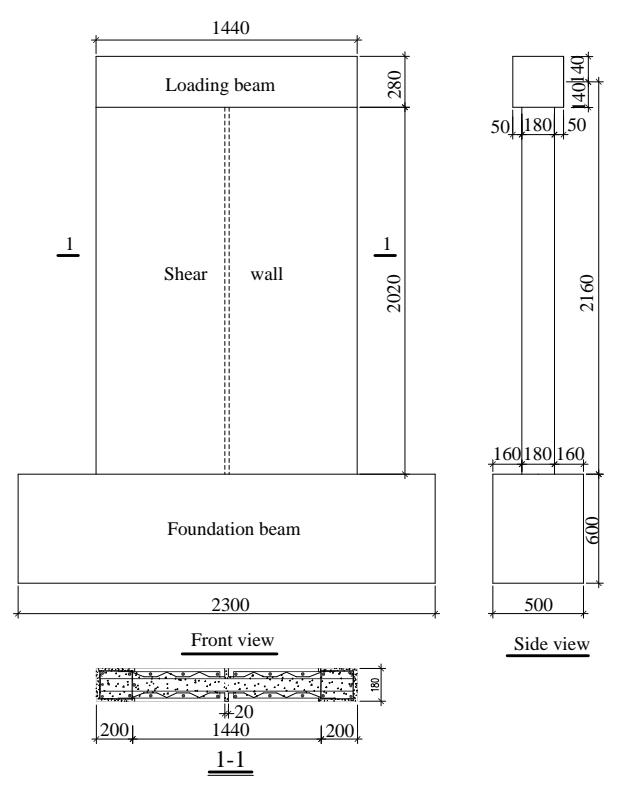

Fig. (1). Dimensions and assembly drawing of specimens. 


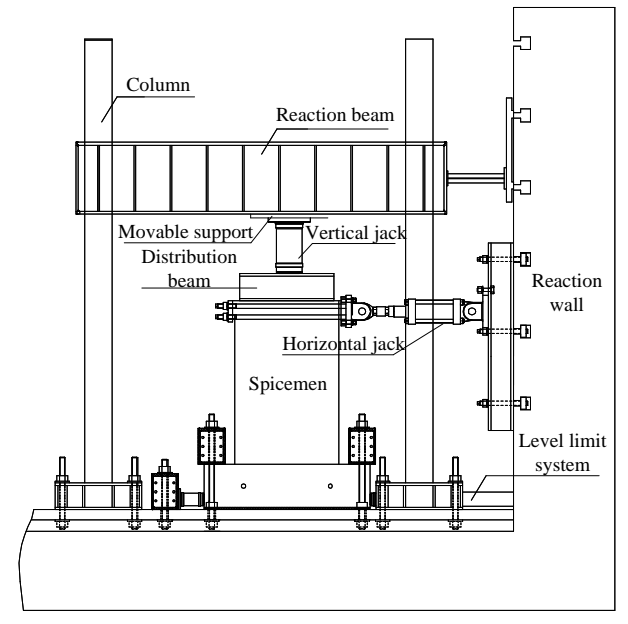

Fig. (2). Test setup.

\section{METERING SCHEME}

Instrumentation was used to measure displacements, loads, and stains at critical locations of the specimen. The main parameters including load, displacement and steel strain were measured in the experiment. There were load transducers to get the value of vertical and horizontal load. The instrumentations used to measure the displacement of the shear wall were displacement meters and relative deformation extensometer. Measurement of the steel strain was accomplished by using wire gages.

\section{Measurement of displacement}

The measurement of displacement included horizontal deformation, vertical and horizontal relative deformation occurring on the concrete of both sides of vertical and inner joint, relative deformation between shear wall and foundation beam, translation and rotation of foundation beam, and so on.

\section{Horizontal Deformation}

Horizontal deformation of the shear wall $\Delta$ is composed of horizontal slip $\Delta_{\mathrm{sl}}$ between shear wall and pedestal, flexural deformation $\Delta_{\mathrm{f}}$, and shear deformation $\Delta_{\mathrm{s}}$. which is shown in Fig. (3).

\section{Horizontal Displacement of the Shear Wall}

Displacement meter MH1 was mounted horizontally on the center of the loading beam to measure the top lateral displacement. Deformation type on the loading process is judged by integral deformation of the shear wall inferred from the horizontal displacement variable curve along the shear wall $[1,2]$. Eight displacement meters (EH1 EH4 and WH1 WH4) of different range were mounted at vertical location along the length of the wall boundaries to measure horizontal displacement. The layout of measurement points is shown in Fig. (4a).

A displacement meter (BH1) was mounted horizontally at the end of the pedestal to measure any horizontal slip of the pedestal along the strong floor. Two additional displacement
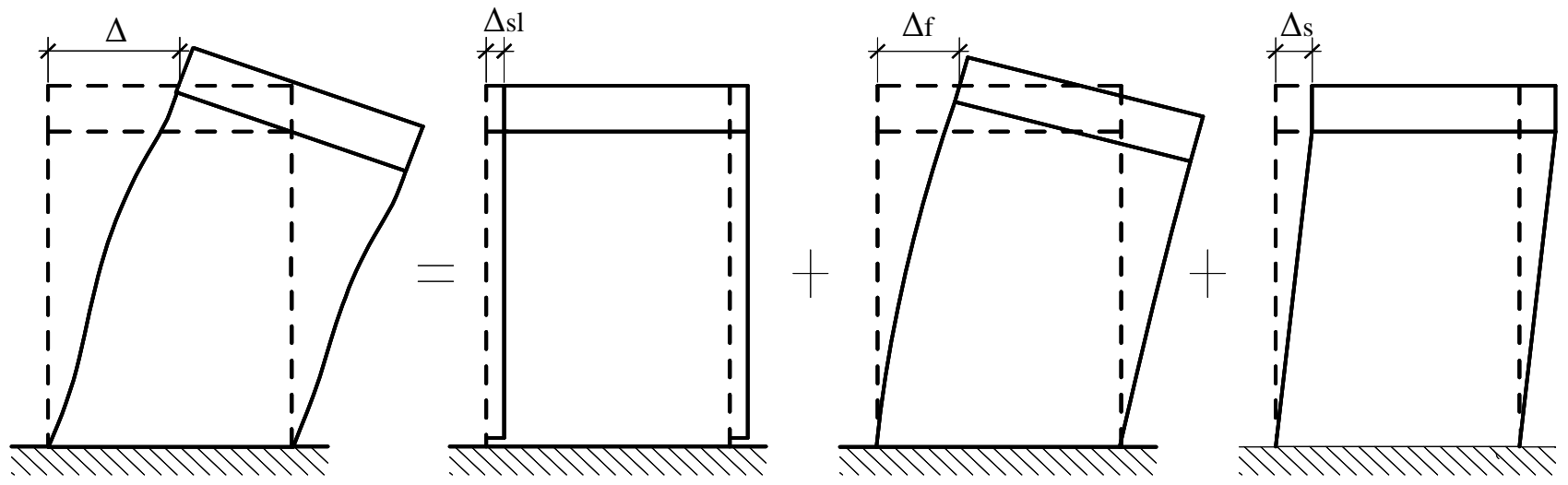

Fig. (3). The composition of lateral deformation in shear wall.

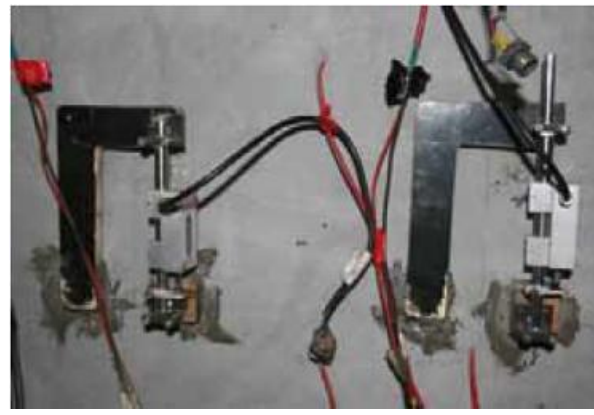

(a) L-type device

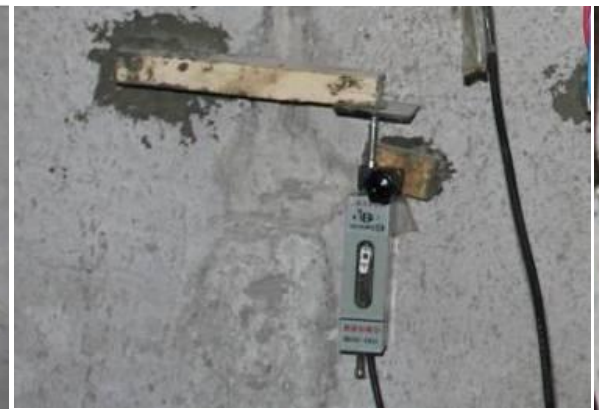

(b) New measurement device

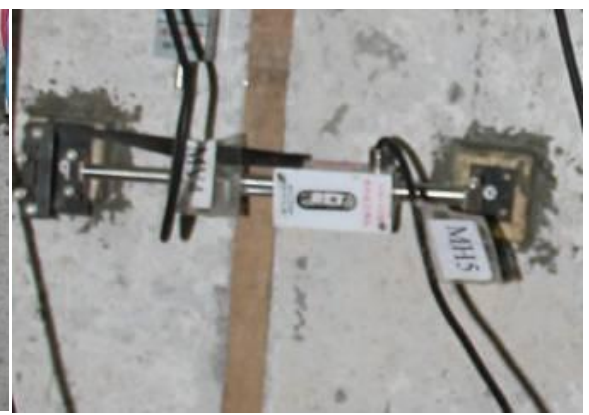

(c) relative deformation extensometer

Fig. (4). The measurement device of relative deformation. 
meters (EV5 and WV5) were mounted vertically at each end of the pedestal to measure rotation caused by the upright of the pedestal from the strong floor. The result was found in the test under ultimate load, the value of the horizontal slip and the lateral displacement causing by rotation was $1.17 \mathrm{~mm}$ and $4.24 \mathrm{~mm}$, accounting for $8.35 \%$ and $12.59 \%$ of the top lateral displacement respectively.

\section{Horizontal slip between Shear Wall and Pedestal $A_{s l}$}

Horizontal slip between shear wall and pedestal was measured by using one horizontal displacement meter (MH8) at the depth of the shear wall. With the principle of strong shearing and weak bending, the crack width on the bottom of the precast concrete shear wall was less than 2 $\mathrm{mm}$, the concrete compression area was large, and the longitudinal reinforcement in the edge of the element was consistently in elastic stage. So the horizontal slip between shear wall and pedestal was a little. The type of displacement meter applied to measure the slip is YHD-20 with measuring accuracy of $0.01 \mathrm{~mm}$. It's shown in the test that the maximum value of the slip was $0.46 \mathrm{~mm}$, accounting for $2.07 \%$ of the top lateral displacement.

\section{Measurement of Flexural Deformation and Shear Deformation}

Shear deformations were measured through the use of wire potentiometers mounted on the bottom (in an $\mathrm{X}$ configuration) of the specimen (see Fig. 5) [3-5]. But the shear deformation was too large by using $X$ configuration due to the effect of flexural deformation [6, 7]. A Reasonable measuring method was that the flexural deformation was obtained from vertical deformation which was measured by using displacement meters mounted directly along the wall boundaries (see Fig. (6)) [7], so the shear deformation was gotten. The result shows that flexural deformation can be calculated accurately by using 4 to 6 vertical displacement meters mounted along the wall edge element.

The sketch of the flexural deformation calculation is shown in Fig. (6). Flexural deformation $\Delta_{\mathrm{f}}$ can be computed

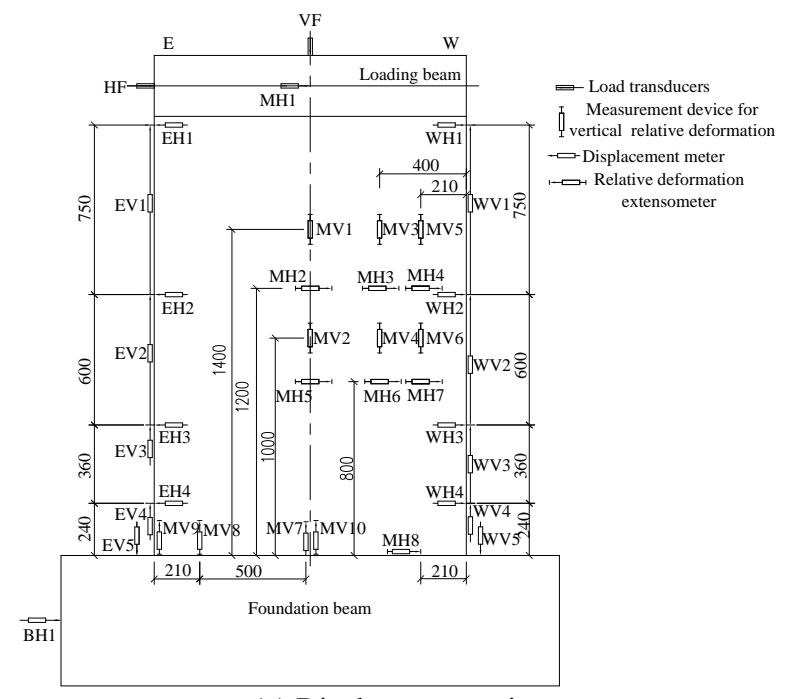

(a) Displacement point

Fig. (5). Layout of measurement points.

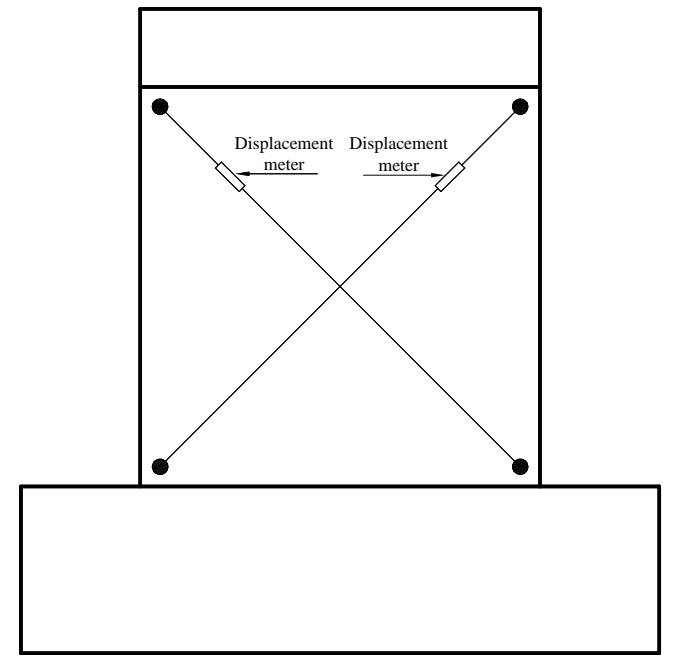

Fig. (6). Shear deformation measurement method.

from the vertical measurements obtained during testing by rearranging Eq. (1) as

$$
\Delta_{\mathrm{f}}=\int_{0}^{h}(h-y) \varphi(y) d y=\sum_{i=1}^{n}\left(\frac{1}{2} \varphi_{i} h_{i}^{2}+\left(h-y_{i}\right) \varphi_{i} h_{i}\right)
$$

where, $y_{\mathrm{i}}$ is the height from the measuring point of vertical displacement to the bottom of the shear wall. $h$ is the story height, and the width of the shear wall is $l . n$ is the number of vertical displacement meters, and is generally set as 4 6. $\varphi_{\mathrm{i}}$ is the sectional curvature and can be computed by Eq. (2).

$\varphi_{i}=\frac{1}{l}\left(\varepsilon_{i}+\varepsilon_{i}^{\prime}\right)$

It is noted that $\varepsilon_{\mathrm{i}}$ and $\varepsilon_{\mathrm{i}}$ ' are the strain value computed by Eq. (2).

$\Delta_{s}=\Delta-\Delta_{f}-\Delta_{s l}$

Eight displacement meters (EV1-EV4 and WV1-WV4) were mounted vertically (Fig. (7a)) at various along the

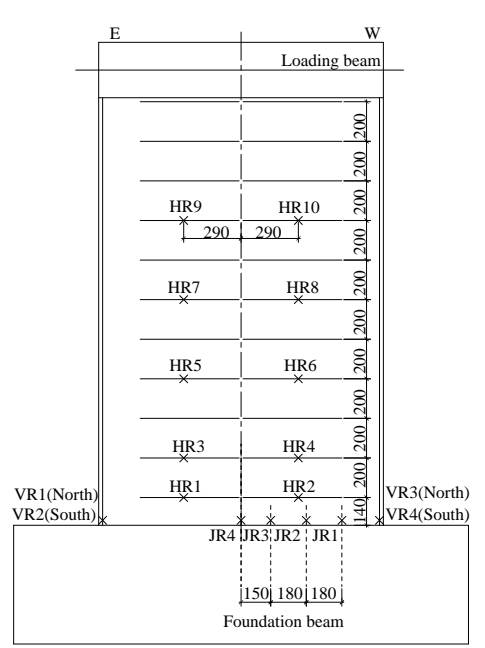

(b) Strain point 


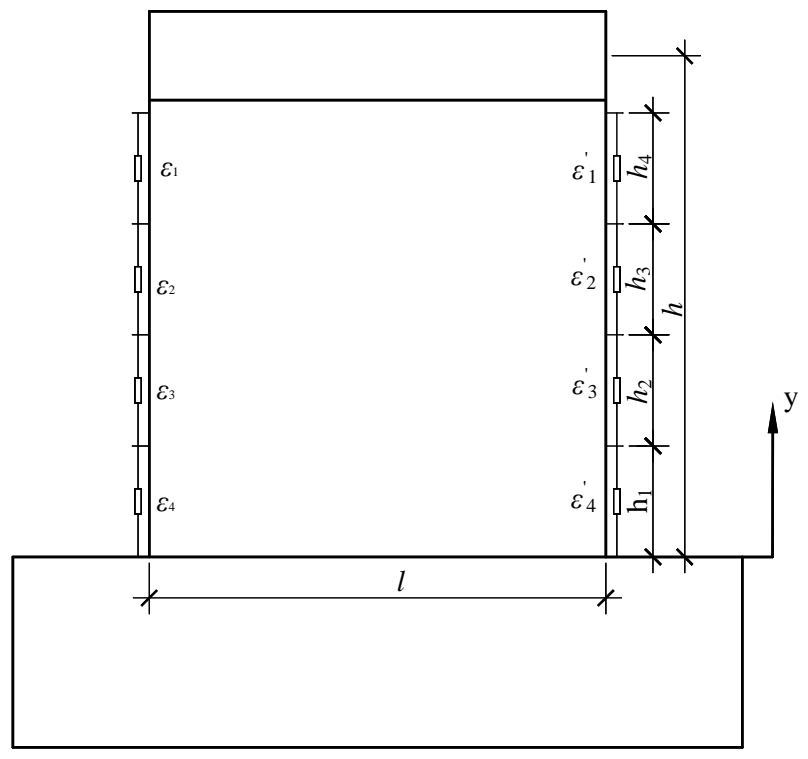

Fig. (7). The sketch of bending deformation calculation.

height of the shear wall so that flex ural deformation could be determined.

\section{The Measurement of Relative Deformation}

There is a vertical joint between two precast two-way hollow slabs in the specimen and relative deformation (including vertical and horizontal) occurs during quasi-static testing. The macroscopically vertical crack was caused by the inner joint between precast concrete and cast-in-place concrete of the holes at the action of the horizontal loading. How to get the relative deformation of vertical cracks and vertical macro-cracks occurring on the concrete of both sides of vertical joints and inner joints is very important to study the mechanical behaviors of the precast concrete shear wall. L-type device (Fig. (4a)) was used to measure the relative deformation of vertical joints in document [8]. When there is horizontal relative deformation on both sides of vertical joint, there will be some errors. In order to avoid the errors, so a new measurement device shown in Fig. (4b) was designed in this experiment. The new measurement device includes a wood bar which is $60 \mathrm{~mm}$ long, a $15 \mathrm{~mm} \times 10 \mathrm{~mm}$ glass slide and a displacement meter with fixing device. The glass slide is adhered on the end of the wood bar, and then the displacement meter is fixed on the below of the glass slide. The displacement meter can slip along the glass to avoid affecting the measuring result of vertical relative deformation when the horizontal relative deformation occurs. The horizontal relative deformation was measured by relative deformation extensometer shown in Fig. (7c).

Layout of displacement measurement points is shown in Fig. (4a). The measurements to measure the relative deformation of the vertical joint were MV1, MV2 and MH2, MH5. The devices MV3, MV4 and MH3, MH4, were used to measure the relative macroscopically vertical crack. The relative deformation between precast two-way hollows slab and edge element was measured by MV5, MV6 and MH4, MH7.

\section{The Measurement of Strains}

The strains in the reinforcing steel were measured through the strain gages. Three types of reinforcement were monitored including transverse steel, longitudinal reinforcement in the edge element, and insert reinforcement. The reinforcements being monitored are shown in Fig. (4b). The strain gages HR1 HR10 were used to measure the strains of transverse steels. Strain gages VR1 VR4 measured the strains of outermost longitudinal reinforcements in the edge of the element. There were four strain gages JR1 JR4 to measure the strains of insert reinforcement.

\section{THE RESULTS OF MEASUREMENT}

The distribution of the lateral displacement along the height of shear wall is shown in Fig. (8). Lateral displacement was measured through the introducing scheme in different loading and top drift ratio. The result shows that the horizontal deformation curve was bending type at the initial stage and then developed into shear-bending type at the last stage.

The top lateral force-flexural deformation and force-shear deformation hysteretic loops of the shear wall were shown in Fig. (9). The study shows that shear deformation of the precast concrete shear wall with strong shearing and weak bending accounts for $60 \% \sim 85 \%$ of the top lateral displacement.

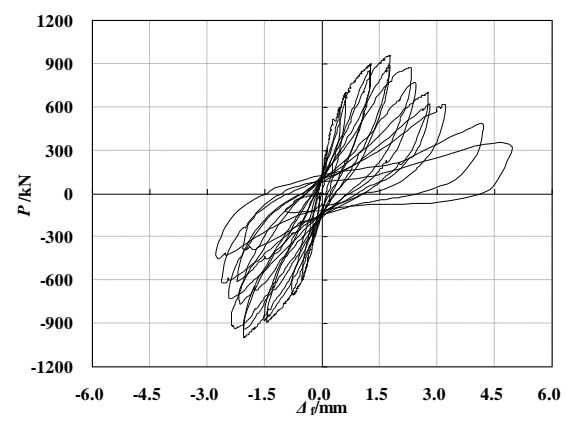

(a) Top lateral force-flexural deformation

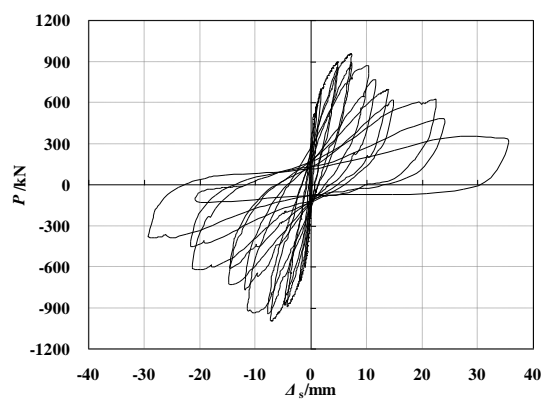

(b) Top lateral force-shear deformation

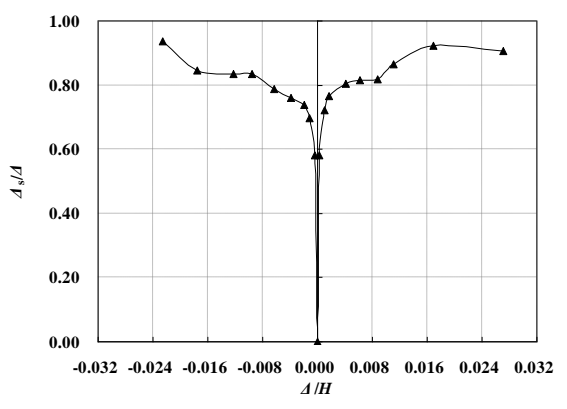

(c) Shear wall deformation percentage

Fig. (8) The component of lateral deformation. 


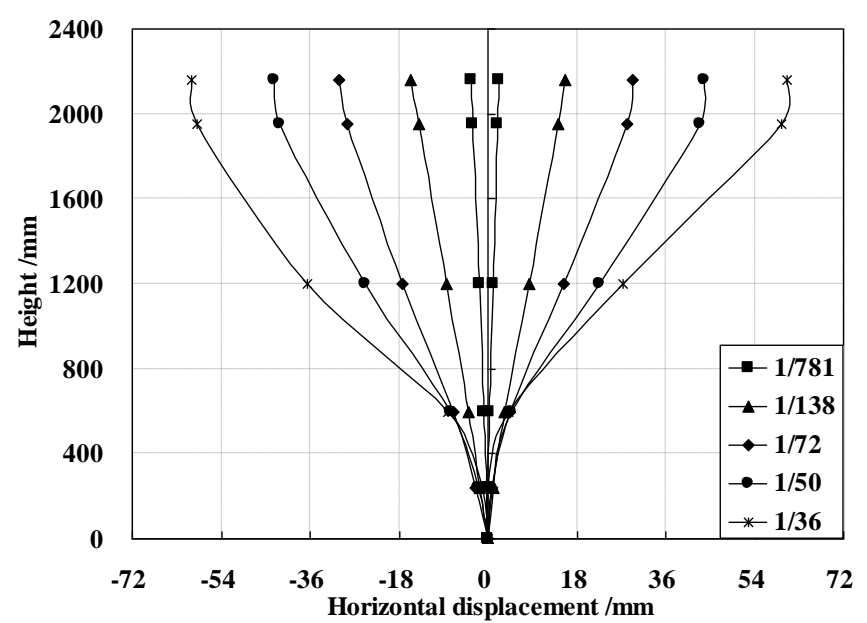

Fig. (9). Horizontal displacement along the wall.

Top lateral force-relative deformation skeleton curves of the vertical joint are shown in Fig. (10a), and the vertical macro-cracks are shown in Fig. (10b). As can be seen in these figures, there is relative deformation on the concrete of both sides of vertical joint, but no vertical macro-cracks, before the peak load. There was some relative deformation on the concrete between the vertical macro-cracks suddenly when the lateral load reached the peak load. After the peak load, the relative deformation increased with the development of lateral load. It is significant to study the phenomenon for researching the mechanical behaviors of the precast concrete shear wall.

\section{CONCLUSION}

Shear deformation is the main portion of the top lateral displacement of the precast concrete shear wall with strong shearing and weak bending. It is significant to research the mechanical behaviors of the precast concrete shear wall to study the horizontal and vertical relative deformation of the vertical joint and inner joints. A precise measuring method for shear deformation is introduced, a new measurement device is used to measure the relative deformation of the vertical joint and inner joints, and the measurement scheme of displacement and strain is presented in this paper. As the results shown, the measurement scheme is reasonable and feasible. It can monitor the response of the precast concrete shear wall built with precast two-way hollow slabs under load, and it can provide some reference for the metering scheme of such structures. The study indicates that the new measurement method can be used in practical engineering.

\section{CONFLICT OF INTEREST}

The authors confirm that this article content has no conflict of interest.

\section{ACKNOWLEDGEMENTS}

The authors are grateful to the support of National Science Foundation of China (Grant No. 51378450) and the Project of Shandong Province Higher Educational Science and Technology Program (Grant No. J13LG09).

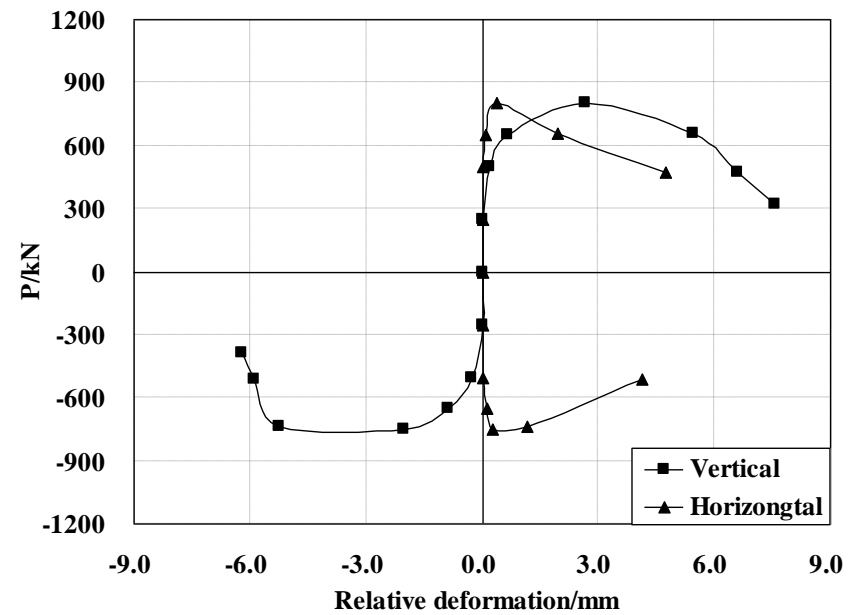

(a) Vertical joint

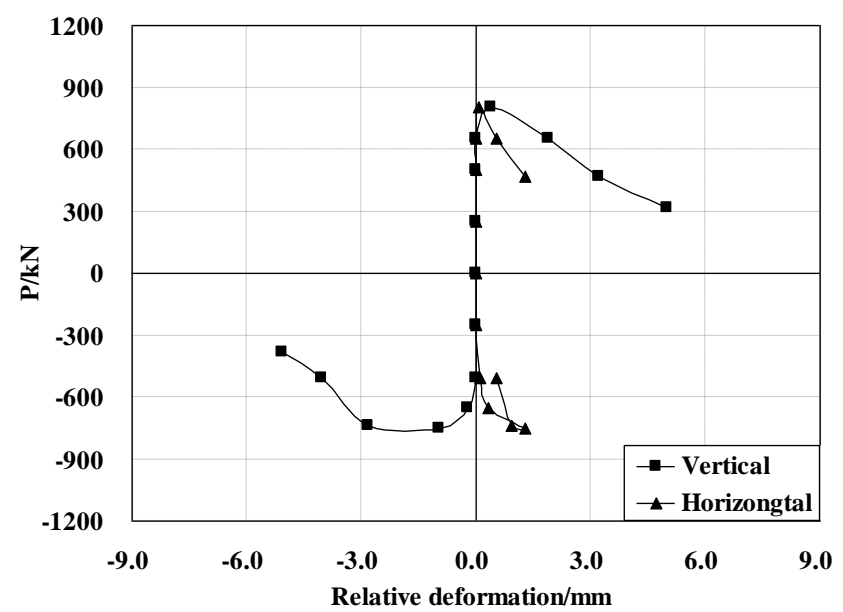

(b) Macroscopically vertical crack

Fig. (10). Relative deformation.

\section{REFERENCES}

[1] M. Chu, J. Liu, H. Cui, J. Hou, Y. Zhou and Z. Zhang, "Experimental study on shear behavior of assembled monolithic concrete shear walls built with precast two-way hollow slabs", Eng. Mech., vol. 30, no. 7, pp.219-229, 2013.

[2] J. Qian, X. Yang, H. Qin, Y. Peng, J. Zhang and J. Li, “Tests on seismic behavior of pre-cast shear walls with various methods of vertical reinforcement splicing", J. Build. Struct., vol. 32, no. 6, pp. 51-59, 2011.

[3] Y. Peng, "Experimental Study on Seismic Behavior of Pre-cast Reinforced Concrete Shear Walls", D. S. thesis, Tsinghua University, Beijing, China, 2010.

[4] J. Nie, H. Hu, S. Li, F. Liu, J. Fan, M. Tao, D. Shao and D. Yu, "Experimental study on seismic behaviors of steel plate reinforced concrete composite shear walls with square CFST concealed columns", J. Build. Struct., vol. 34, no. 1, pp. 52-60, 2013.

[5] X. Lv, C. Gan and W. Wang, "Study on seismic behavior of steel plate reinforced concrete shear walls", J. Build. Struct., vol. 30, no. 5, pp. 89-95, 2009.

[6] M. Chu, "Seismic Behavior of Cold-formed Thin-walled Steel Reinforcement Concrete Shear Walls", D. S. thesis, Tsinghua University, Beijing, 2010. 
[7] L. M. Massone and J. W. Wallace. "Load-deformation response of slender reinforced concrete walls", ACI Struct. J., vol. 101, no. 1, pp. 103-113, 2004
[8] M. Chu, P. Feng, L. Ye, J. Hou, "Experimental study on shear behaviors of cold-formed thin-walled steel reinforced concrete shear walls with different details", Eng. Mech., vol. 28, no. 8, pp. $45-55,2011$.

Received: February 11, 2014

Revised: February 19, 2014

Accepted: February 28, 2014

(c) Sun et al.; Licensee Bentham Open.

This is an open access article licensed under the terms of the Creative Commons Attribution Non-Commercial License (http://creativecommons.org/licenses/ by-nc/3.0/) which permits unrestricted, non-commercial use, distribution and reproduction in any medium, provided the work is properly cited. 